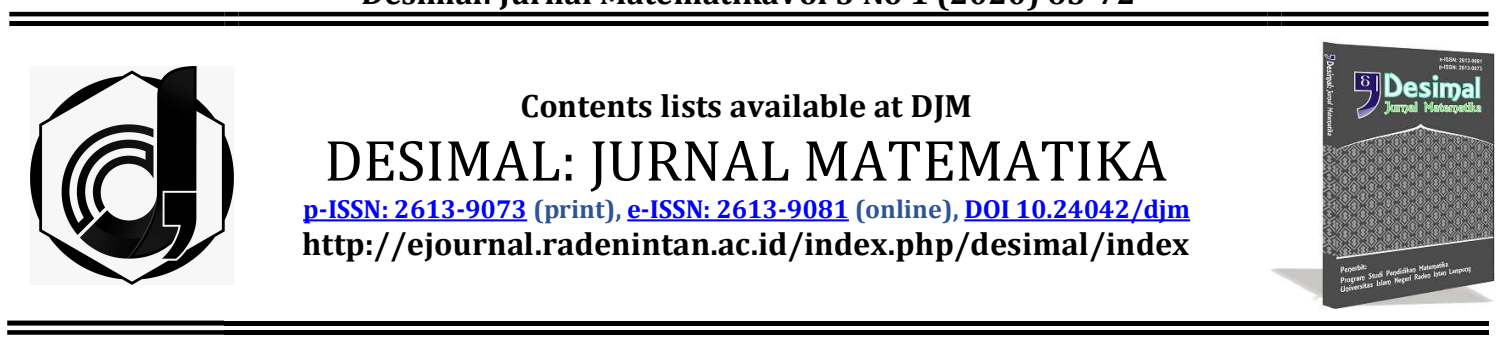

\title{
Odd Harmonious Labeling on Edge Amalgamation from Double Quadrilateral Graphs
}

Fery Firmansah*, Tasari

Universitas Widya Dharma Klaten, Indonesia

\author{
ARTICLE INFO

\section{Article History} \\ Received : 19-07-2019 \\ Revised : 23-11-2019 \\ Accepted : 15-01-2020 \\ Published : 26-01-2020 \\ Keywords: \\ Double quadrilateral; \\ Edge amalgamation; \\ Graph labeling. \\ Odd harmonious graph; \\ *Correspondence: E-mail: \\ feryfirmansah@unwidha.ac.id \\ Doi: \\ $\underline{10.24042 / \text { djm.v3i1.5712 }}$
}

\begin{abstract}
A graph that has odd harmonious labeling properties is called an odd harmonious graph. The purpose of this research is to obtain a new class graphs construction which is a family of odd harmonious graphs. The research method used consisted of several stages, namely research preparation, research investigation and verification of research results. The results of this study, we will give a edge amalgamation construction of $\boldsymbol{n}$ double quadrilateral graphs $\boldsymbol{D Q}$, denoted by $\circledast \boldsymbol{D Q}(\boldsymbol{n})$ and graph obtained by connecting between two graphs $\circledast \boldsymbol{D Q}(\boldsymbol{n})$ with line graph $\boldsymbol{L}_{2}$, denoted by $\circledast\left(\boldsymbol{D Q}(\boldsymbol{n}), \boldsymbol{L}_{2}, \boldsymbol{D Q}(\boldsymbol{n})\right)$. It has further been proven that graph $\circledast \boldsymbol{D Q}(\boldsymbol{n})$ and graph $\circledast\left(\boldsymbol{D Q}(\boldsymbol{n}), \boldsymbol{L}_{2}, \boldsymbol{D Q}(\boldsymbol{n})\right)$ have odd harmonious labeling properties, such that all of them are odd harmonious graphs.
\end{abstract}

\section{INTRODUCTION}

Graph labeling has become a combinatoric field that has developed very rapidly in recent years both in theory and application research on labeling graphs is very important because in several journals submitted by Gallian in 2019, it is evident that graph labeling can be applied to various scientific fields between others are coding theory, data base management, secret sharing schemes and cryptography. Graph labeling is the mapping of a set of points, a set of lines or a combination of both to positive numbers with certain properties (Gallian, 2019).
One new type of labeling of graphs is the labeling of odd harmonious graphs discovered by Liang and Bai in 2009. Previously in 1980 Graham and Sloane introduced the definition of harmonious graphs. Harmonious graph $G(p, q)$ is a graph that fulfills the properties of the harmonious labeling function, namely that there is an injective vertex labeling function $f: V(G) \rightarrow Z_{q}$ in such a way as to induce a function of labeling the edge that is wise $\quad f^{*}: E(\mathrm{G}) \rightarrow Z_{q}$ with $f^{*}(x y)=(f(x)+f(y)) \bmod q \quad$ is $\quad$ a bijective function and $Z_{q}$ is a set of modulo integers $q$ (Liang \& Bai, 2009). 
Liang and Bai extended the definition of harmonious graph to the odd harmonious graph definition. Odd harmonious graphs are graphs $G(p, q)$ which have the properties of the odd harmonious labeling function, there is an injection function $f: V(G) \rightarrow$ $\{0,1,2,3, \ldots, 2 q-1\}$ such that the induced function $f^{*}: E(\mathrm{G}) \rightarrow\{1,3,5,7, \ldots, 2 q-1\}$ defined by $f^{*}(x y)=f(x)+f(y)$ is an bijection (Liang \& Bai, 2009).

Relevant research results can be seen in some of the published journals and proceedings, among others. The generalized prism graph is an odd harmonious graph (Saputri, Sugeng, \& Froncek, 2013), union of snake graphs and pleated of snake graphs are odd harmonious graph (Firmansah, 2016), the Dutch windmill graph is an odd harmonious graph (Firmansah \& Yuwono, 2017a), Cartesian product operation results graphs are odd harmonious graph (Firmansah \& Yuwono, 2017b), the variation of the double quadrilateral windmill graphs are odd harmonious graph (Firmansah, 2017), amalgamation of the Dutch windmill graphs are odd harmonious graph (Firmansah \& Wahid Syaifuddin, 2018), grid graph is an odd harmonious graphs (Jeyanthi, Philo, \& Youssef, 2019), super subdevision graphs are odd harmonious graphs (Jeyanthi, Philo, \& Siddiqui, 2019).

Double quadrilateral windmill graphs $D Q^{(n)}$ and amalgamation of double quadrilateral windmill graphs $D Q^{(n)} *$ $L_{2} * D Q^{(n)}$ are odd harmonious graph (Firmansah \& Syaifuddin, 2018). In this study, the authors are interested in constructing a new graph $\circledast D Q(n)$. The fundamental difference between graphs $D Q^{(n)}$ with graphs $\circledast D Q(n)$ lies in the amalgamation operation used. Graph $D Q^{(n)}$ formed from $n$ graph double quadrilateral $D Q$ with vertex amalgamation operation, while graphs $\circledast$ $D Q(n)$ formed from $n$ double quadrilateral graph $D Q$ with edge amalgamation operation, denoted by $\circledast$ $D Q(n)=D Q * D Q * D Q * \ldots * D Q$.

The author also developed a graph $\circledast D Q(n)$ will become graph $\circledast$ $\left(D Q(n), L_{2}, D Q(n)\right)=D Q * D Q * \ldots * D Q *$ $L_{2} * D Q * D Q * \ldots * D Q$ that is, the graph obtained by connecting between two graphs $\circledast D Q(n)$ with line graphs $L_{2}$. Furthermore, graph $\circledast D Q(n)$ and graph $\circledast\left(D Q(n), L_{2}, D Q(n)\right)$ both of them will be proven have odd harmonious labeling function such that it is an odd harmonious graph.

The results of this study proved to be able to add scientific insights in the field of combinatorics especially for the development of graph labeling theory. More specifically the development of the theory of odd harmonious graph labeling. Namely by getting a new graph class which is a family of odd harmonious graphs.

\section{METHOD}

The research method used in this study consisted of several stages. The first stage is the preparation of research which is to construct the construction of a new graph to get a vertex set, edge set, size and order of a graph. The second stage is a research investigation which is to provide a vertex label on the graph which is injective and an edge label that is bijective which meets the properties of the odd harmonious labeling function. The third stage is the verification of the results of the research in the form of theorem construction accompanied by mathematical proof. The final stage is to give an example of label construction on a simple graph to facilitate understanding.

\section{RESULTS AND DISCUSSION}

The results and discussion in this study are stated in the form of the construction of definitions and theorems and their proofs.

Edge amalgamation operation from graph $G$ and graph $H$ denoted by $G * H$ is a graph operation that combines edges $a b \in$ 
$G$ and $c d \in H$ into one edge $u v \in G * H$. Symbol $\circledast G(n)=G * G * G * \ldots * G$ express the edge amalgamation of as many graphs G.

Definition 1. Graph $\circledast D Q(n)=$ $D Q * D Q * D Q * \ldots * D Q$ is a graph obtained from $n$ double quadrilateral graphs $D Q$ with edge amalgamation operation.

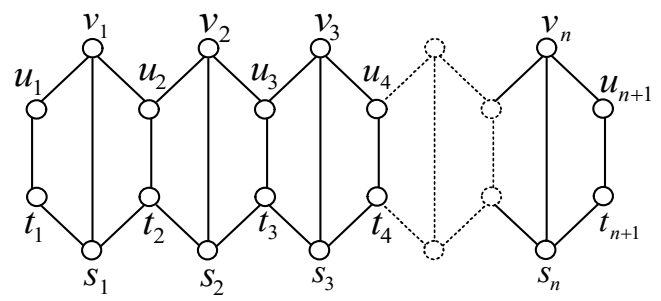

Figure 1. Construction and vertex notation of a graph $\circledast D Q(n)$

Based on Figure 1 obtained

$V(\circledast D Q(n))=\left\{s_{i} \mid 1 \leq i \leq n\right\} \cup$

$\left\{t_{i} \mid 1 \leq i \leq n+1\right\} \cup\left\{u_{i} \mid 1 \leq i \leq n+1\right\} \cup$

$\left\{v_{i} \mid 1 \leq i \leq n\right\}$ and

$E(\circledast D Q(n))=\left\{s_{i} t_{i} \mid 1 \leq i \leq n\right\} \cup$

$\left\{s_{i} t_{i+1} \mid 1 \leq i \leq n\right\} \cup\left\{s_{i} v_{i} \mid 1 \leq i \leq n\right\} \cup$

$\left\{t_{i} u_{i} \mid 1 \leq i \leq n+1\right\} \cup\left\{u_{i} v_{i} \mid 1 \leq i \leq n\right\} \cup$

$\left\{u_{i+1} v_{i} \mid 1 \leq i \leq n\right\}$

then obtained order $p=4 n+2$ and size $q=6 n+1$.

Theorem 1. Graph $\circledast D Q(n)$ is an odd harmonious graph.

Proof:

Defined the vertex labeling function

$f: V(\circledast D Q(n)) \rightarrow\{0,1,2,3, \ldots, 12 n+1\}$ as follows:

$f\left(s_{i}\right)=2 i-2,1 \leq i \leq n$

$f\left(t_{i}\right)=4 i-3,1 \leq i \leq n+1$

$f\left(u_{i}\right)=6 n+2 i-2,1 \leq i \leq n+1(1.3)$

$f\left(v_{i}\right)=4 i-1,1 \leq i \leq n$

It will be shown that the function $f$

injective. Based on the equation (1.1),

(1.2), (1.3), and (1.4) obtained.

(a) The value of the label for each vertex is

$0,2,4,6, \ldots, 2 n-2 \equiv 2(\bmod 2)$,

$1,5,9,13, \ldots, 4 n+1 \equiv 1(\bmod 4)$,

$6 n, 6 n+2,6 n+4,6 n+8 \ldots, 8 n \equiv$

$6 n(\bmod 2)$, and
$3,7,11,15, \ldots, 4 n-1 \equiv 3(\bmod 4)$. so each vertex has a different label.

(b) Vertex set after labeling $f(V(\circledast D Q(n)))=\{0,2,4,6, \ldots, 2 n-$ 2) $\cup\{1,5,9,13, \ldots, 4 n+1\} \cup\{6 n, 6 n+$ $2,6 n+4,6 n+8, \ldots, 8 n\} \cup$ $\{3,7,11,15, \ldots, 4 n-1\}$ $=\{0,1,2,3,4,5,6,7,8,9, \ldots, 2 n-2,4 n-$ $1,4 n+1,6 n, 6 n+2,6 n+4,6 n+$ $8, \ldots, 8 n\}=\{0,1,2,3, \ldots, 8 n\}$ $\subseteq\{0,1,2,3, \ldots, 12 n+1\}$

Then based on (a) and (b) it is proven that the function $f$ injective.

Next is defined edge labeling function $\quad f^{*}: E(\circledast D Q(n)) \rightarrow$ $\{1,3,5,7, \ldots, 12 n+1\}$ as follows: $f^{*}\left(s_{i} t_{i}\right)=6 i-5,1 \leq i \leq n$ $f^{*}\left(s_{i} t_{i+1}\right)=6 i-1,1 \leq i \leq n$

$f^{*}\left(s_{i} v_{i}\right)=6 i-3,1 \leq i \leq n$

$f^{*}\left(t_{i} u_{i}\right)=6 n+6 i-5,1 \leq i \leq n+1$

$f^{*}\left(u_{i} v_{i}\right)=6 n+6 i-3,1 \leq i \leq n$

$f^{*}\left(u_{i+1} v_{i}\right)=6 n+6 i-1,1 \leq i \leq n$ (1.10)

It will be shown that the function $f^{*}$ bijective. Based on the equation (1.5), (1.6), (1.7), (1.8), (1.9) and (1.10) obtained.

(c) The label value of each edge is $1,7,13,19, \ldots, 6 n-5 \equiv 1(\bmod 6)$,

$5,11,17,23, \ldots, 6 n-1 \equiv 5(\bmod 6)$, $3,9,15,21, \ldots, 6 n-3 \equiv 3(\bmod 6)$,

$6 n+1,6 n+7,6 n+13,6 n+$ $19, \ldots, 12 n+1 \equiv 1(\bmod 6)$, $6 n+3,6 n+9,6 n+15,6 n+$ $21, \ldots, 12 n-3 \equiv 3(\bmod 6)$, and $6 n+5,6 n+11,6 n+17,6 n+$ $23, \ldots, 12 n-1 \equiv 5(\bmod 6)$ so that each edge has a different label.

(d) Edge set after labeling

$f^{*}(E(\circledast D Q(n)))=$

$\{1,7,13,19, \ldots, 6 n-5\} \cup$

$\{5,11,17,23, \ldots, 6 n-1\} \cup$

$\{3,9,15,21, \ldots, 6 n-3\} \cup\{6 n+1,6 n+$

$7,6 n+13,6 n+19, \ldots, 12 n+1\} \cup$

$\{6 n+3,6 n+9,6 n+15,6 n+$

$21, \ldots, 12 n-3\} \cup\{6 n+5,6 n+$

$11,6 n+17,6 n+23, \ldots, 12 n-1\}$

$=\{1,3,5,7,9,11,13,15,17,19, \ldots, 6 n-$

$5,6 n-3,6 n-1,6 n+1,6 n+3,6 n+$ 
Desimal, 3 (1), 2020 - 68

Fery Firmansah, Tasari

$5,6 n+7,6 n+9,6 n+11,6 n+$ $13,6 n+15,6 n+17,6 n+$

$19, \ldots, 12 n-3,12 n-1,12 n+1\}$

$=\{1,3,5,7, \ldots, 12 n+1\}$

Then based on (c) and (d) it is proven that the function $f^{*}$ bijective.

Furthermore, because function $f$ injective such that the induced function $f^{*}$ bijective then graph $\circledast D Q(n)$ is an odd harmonious graph.

Example 1. Here are given odd harmonious labeling on the graph $\circledast$ $D Q(6)$ (Figure 2) and $\circledast D Q(7)$ (Figure 3 ).

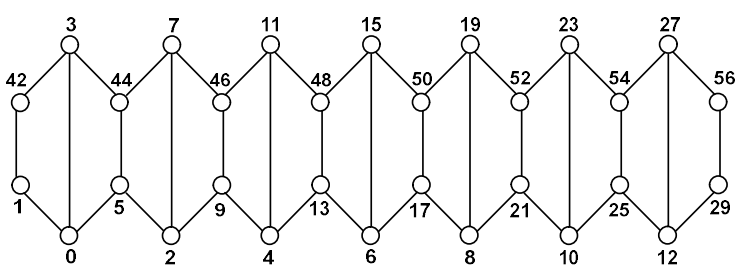

Figure 3. Odd harmonious labeling on a graph $\circledast D Q(7)$

Definition 2. Graph $\circledast$

$\left(D Q(n), L_{2}, D Q(n)\right)=D Q * D Q * \ldots * D Q *$ $L_{2} * D Q * D Q * \ldots * D Q$ is a graph obtained by connecting between two graphs $\circledast$ $D Q(n)$ with line graph $L_{2}$.

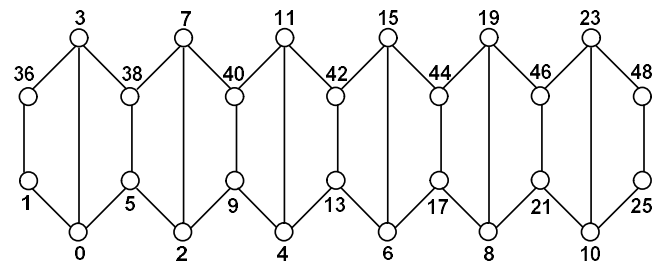

Figure 2. Odd harmonious labeling on a graph $\circledast D Q(6)$

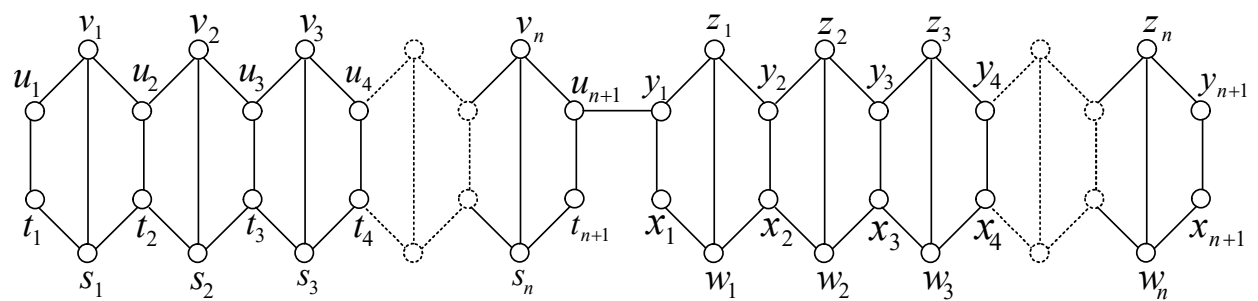

Figure 4. Construction and vertex notation of a graph $\circledast\left(D Q(n), L_{2}, D Q(n)\right)$.

Based on Figure 4 obtained

$V\left(\circledast\left(D Q(n), L_{2}, D Q(n)\right)\right)=$

$\left\{s_{i} \mid 1 \leq i \leq n\right\} \cup\left\{t_{i} \mid 1 \leq i \leq n+1\right\} \cup$

$\left\{u_{i} \mid 1 \leq i \leq n+1\right\} \cup\left\{v_{i} \mid 1 \leq i \leq n\right\} \cup$

$\left\{w_{i} \mid 1 \leq i \leq n\right\} \cup\left\{x_{i} \mid 1 \leq i \leq n+1\right\} \cup$

$\left\{y_{i} \mid 1 \leq i \leq n+1\right\} \cup\left\{z_{i} \mid 1 \leq i \leq n\right\}$ and

$E\left(\circledast\left(D Q(n), L_{2}, D Q(n)\right)\right)=$

$\left\{s_{i} t_{i} \mid 1 \leq i \leq n\right\} \cup\left\{s_{i} t_{i+1} \mid 1 \leq i \leq n\right\} \cup$

$\left\{s_{i} v_{i} \mid 1 \leq i \leq n\right\} \cup\left\{t_{i} u_{i} \mid 1 \leq i \leq n+1\right\} \cup$

$\left\{u_{i} v_{i} \mid 1 \leq i \leq n\right\} \cup\left\{u_{i+1} v_{i} \mid 1 \leq i \leq n\right\} \cup$

$\left\{u_{n+1} y_{1}\right\} \cup\left\{w_{i} x_{i} \mid 1 \leq i \leq n\right\} \cup$

$\left\{w_{i} x_{i+1} \mid 1 \leq i \leq n\right\} \cup\left\{w_{i} z_{i} \mid 1 \leq i \leq n\right\} \cup$

$\left\{x_{i} y_{i} \mid 1 \leq i \leq n+1\right\} \cup\left\{y_{i} z_{i} \mid 1 \leq i \leq n\right\} \cup$

$\left\{y_{i+1} z_{i} \mid 1 \leq i \leq n\right\}$

an order is obtained $p=8 n+4$ and size

$q=12 n+3$.
Theorem 2. Graph $\circledast\left(D Q(n), L_{2}, D Q(n)\right)$ is an odd harmonious graph.

Proof:

Defined the vertex labeling function

$f: V\left(\circledast\left(D Q(n), L_{2}, D Q(n)\right)\right) \rightarrow$

$\{0,1,2,3, \ldots, 24 n+5\}$ as follows :

$f\left(s_{i}\right)=2 i-2,1 \leq i \leq n$

$f\left(t_{i}\right)=4 i-3,1 \leq i \leq n+1$

$f\left(u_{i}\right)=6 n+2 i-2,1 \leq i \leq n+1$

$f\left(v_{i}\right)=4 i-1,1 \leq i \leq n$

$f\left(w_{i}\right)=4 n+4 i+1,1 \leq i \leq n$

$f\left(x_{i}\right)=14 n+2 i, 1 \leq i \leq n+1$

$f\left(y_{i}\right)=4 n+4 i-1,1 \leq i \leq n+1$ (2.7)

$f\left(z_{i}\right)=8 n+2 i, 1 \leq i \leq n$

It will be shown that the function $f$

injective. Based on the equation (2.1), 
Desimal, 3 (1), 2020 - 69

Fery Firmansah, Tasari

(2.2), (2.3), (2.4), (2.5), (2.6), (2.7) and (2.8) obtained

(a) The value of the label for each vertex is

$0,2,4,6, \ldots, 2 n-2 \equiv 2(\bmod 2)$, $1,5,9,13, \ldots, 4 n+1 \equiv 1(\bmod 4)$, $6 n, 6 n+2,6 n+4,6 n+8 \ldots, 8 n \equiv$ $6 n(\bmod 2)$,

$3,7,11,15, \ldots, 4 n-1 \equiv 3(\bmod 4)$, $4 n+5,4 n+9,4 n+13,4 n+$ $17, \ldots, 8 n+1 \equiv 1(\bmod 4)$, $14 n+2,14 n+4,14 n+6,14 n+$ $8, \ldots, 16 n+2 \equiv 14 n(\bmod 2)$, $4 n+3,4 n+7,4 n+11,4 n+$ $15, \ldots, 8 n+3 \equiv 3(\bmod 4)$, and $8 n+2,8 n+4,8 n+6,8 n+$ $8, \ldots, 10 n \equiv 8 n(\bmod 2)$,

so each vertex has a different label.

(b) Vertex set after labeling $f\left(V\left(\circledast\left(D Q(n), L_{2}, D Q(n)\right)\right)\right)=$ $\{0,2,4,6, \ldots, 2 n-2\} \cup$ $\{1,5,9,13, \ldots, 4 n+1\} \cup\{6 n, 6 n+$ $2,6 n+4,6 n+8, \ldots, 8 n\} \cup$ $\{3,7,11,15, \ldots, 4 n-1\} \cup\{4 n+5,4 n+$ $9,4 n+13,4 n+17, \ldots, 8 n+1\} \cup$ $\{14 n+2,14 n+4,14 n+6,14 n+$ $8, \ldots, 16 n+2\} \cup\{4 n+3,4 n+7,4 n+$ $11,4 n+15, \ldots, 8 n+3\} \cup\{8 n+$ $2,8 n+4,8 n+6,8 n+8, \ldots, 10 n\}$ $=\{0,1,2,3,4,5,6,7,8,9, \ldots, 2 n-2,4 n-$ $1,4 n+1,4 n+3,4 n+5,4 n+7,4 n+$ $9,4 n+11,4 n+13,4 n+15,4 n+$ $17, \ldots, 6 n, 6 n+2,6 n+4,6 n+$ $8, \ldots, 8 n, 8 n+1,8 n+2,8 n+3,8 n+$ $4,8 n+6,8 n+8, \ldots, 10 n, 14 n+$ $2,14 n+4,14 n+6,14 n+8, \ldots, 16 n+$ 2\} $=\{0,1,2,3, \ldots, 16 n+2\}$

Then based on (a) and (b) it is proven that the function $f$ injective.

function

Next is defined edge labeling

$f^{*}: E\left(\circledast\left(D Q(n), L_{2}, D Q(n)\right)\right) \rightarrow$

$\{1,3,5,7, \ldots, 24 n+5\}$ as follows:

$f^{*}\left(s_{i} t_{i}\right)=6 i-5,1 \leq i \leq n$

$f^{*}\left(s_{i} t_{i+1}\right)=6 i-1,1 \leq i \leq n$

$f^{*}\left(s_{i} v_{i}\right)=6 i-3,1 \leq i \leq n$

$f^{*}\left(t_{i} u_{i}\right)=6 n+6 i-5,1 \leq i \leq n+1$ $f^{*}\left(u_{i} v_{i}\right)=6 n+6 i-3,1 \leq i \leq n$ $f^{*}\left(u_{i+1} v_{i}\right)=6 n+6 i-1,1 \leq i \leq n(2.14)$ $f^{*}\left(u_{n+1} y_{1}\right)=12 n+3$

$f^{*}\left(w_{i} x_{i}\right)=18 n+6 i+1,1 \leq i \leq n(2.16)$

$f^{*}\left(w_{i} x_{i+1}\right)=18 n+6 i+3,1 \leq i \leq n \quad$ (2.17)

$f^{*}\left(w_{i} z_{i}\right)=12 n+6 i+1,1 \leq i \leq n$ (2.18)

$f^{*}\left(x_{i} y_{i}\right)=18 n+6 i-1,1 \leq i \leq n+1(2.19)$

$f^{*}\left(y_{i} z_{i}\right)=12 n+6 i-1,1 \leq i \leq n$ (2.20)

$f^{*}\left(y_{i+1} z_{i}\right)=12 n+6 i+3,1 \leq i \leq n \quad$ (2.21)

It will be shown that the function $f^{*}$ bijective. Based on the equation (2.9), (2.10), (2.11), (2.12), (2.13), (2.14), (2.15), (2.16), (2.17), (2.18), (2.19), (2.20), and (2.21) obtained

(c) The label value of each edge is $1,7,13,19, \ldots, 6 n-5 \equiv 1(\bmod 6)$, $5,11,17,23, \ldots, 6 n-1 \equiv 5(\bmod 6)$, $3,9,15,21, \ldots, 6 n-3 \equiv 3(\bmod 6)$, $6 n+1,6 n+7,6 n+13,6 n+$ $19, \ldots, 12 n+1 \equiv 1(\bmod 6)$, $6 n+3,6 n+9,6 n+15,6 n+$ $21, \ldots, 12 n-3 \equiv 3(\bmod 6)$, $6 n+5,6 n+11,6 n+17,6 n+$ $23, \ldots, 12 n-1 \equiv 5(\bmod 6)$, $12 n+3 \equiv 3(\bmod 6)$, $18 n+7,18 n+13,18 n+19,18 n+$ $25, \ldots, 24 n+1 \equiv 1(\bmod 6)$, $18 n+9,18 n+15,18 n+21,18 n+$ $27, \ldots, 24 n+3 \equiv 3(\bmod 6)$, $12 n+7,12 n+13,12 n+19,12 n+$ $25, \ldots, 18 n+1 \equiv 1(\bmod 6)$, $18 n+5,18 n+11,18 n+17,18 n+$ $23, \ldots, 24 n+5 \equiv 5(\bmod 6)$, $12 n+5,12 n+11,12 n+17,12 n+$ $23, \ldots, 18 n-1 \equiv 5(\bmod 6)$, and $12 n+9,12 n+15,12 n+21,12 n+$ $27, \ldots, 18 n+3 \equiv 3(\bmod 6)$ so that each edge has a different label.

(d) Edge set after labeling

$$
\begin{aligned}
& f^{*}\left(E\left(\circledast\left(D Q(n), L_{2}, D Q(n)\right)\right)\right)= \\
& \{1,7,13,19, \ldots, 6 n-5\} \cup \\
& \{5,11,17,23, \ldots, 6 n-1\} \cup \\
& \{3,9,15,21, \ldots, 6 n-3\} \cup\{6 n+1,6 n+ \\
& 7,6 n+13,6 n+19, \ldots, 12 n+1\} \cup \\
& \{6 n+3,6 n+9,6 n+15,6 n+ \\
& 21, \ldots, 12 n-3\} \cup\{6 n+5,6 n+ \\
& 11,6 n+17,6 n+23, \ldots, 12 n-1\} \cup \\
& \{12 n+3\} \cup\{18 n+7,18 n+
\end{aligned}
$$


Desimal, 3 (1), 2020 - 70

Fery Firmansah, Tasari

$13,18 n+19,18 n+25, \ldots, 24 n+1\} \cup$ $\{18 n+9,18 n+15,18 n+21,18 n+$ $27, \ldots, 24 n+3\} \cup\{12 n+7,12 n+$ $13,12 n+19,12 n+25, \ldots, 18 n+1\} \cup$ $\{18 n+5,18 n+11,18 n+17,18 n+$ $23, \ldots, 24 n+5\} \cup\{12 n+5,12 n+$ $11,12 n+17,12 n+23, \ldots, 18 n-1\} \cup$ $\{12 n+9,12 n+15,12 n+21,12 n+$ $27, \ldots, 18 n+3\}$

$=\{1,3,5,7,9,11,13,15,17,19, \ldots, 6 n-$ $5,6 n-3,6 n-1,6 n+1,6 n+3,6 n+$ $5,6 n+7,6 n+9,6 n+11,6 n+$ $13,6 n+15,6 n+17,6 n+$ $19, \ldots, 12 n-3,12 n-1,12 n+$ $1,12 n+3,12 n+5,12 n+7,12 n+$ $9,12 n+11,12 n+13,12 n+15,12 n+$ $17,12 n+19,12 n+21,12 n+$ $23, \ldots, 18 n-1,18 n+1,18 n+$ $3,18 n+5,18 n+7,18 n+9,18 n+$

$$
\begin{aligned}
& 11,18 n+13,18 n+15,18 n+ \\
& 17,18 n+19,18 n+21,18 n+ \\
& 23,18 n+25,18 n+27,18 n+ \\
& 29, \ldots, 24 n+1,24 n+3,24 n+5\} \\
& =\{1,3,5,7, \ldots, 24 n+5\}
\end{aligned}
$$

Then based on (c) and (d) it is proven that the function $f^{*}$ bijective.

Furthermore, because function $f$ injective such that the induced function $f^{*}$ bijective then graph $\circledast$ $\left(D Q(n), L_{2}, D Q(n)\right)$ is an odd harmonious graph.

Example 2. Here are given odd harmonious labeling on a graph $\circledast$ $\left(D Q(5), L_{2}, D Q(5)\right)$ (Figure 5) and $\circledast$ $\left(D Q(6), L_{2}, D Q(6)\right)$ (Figure 6).

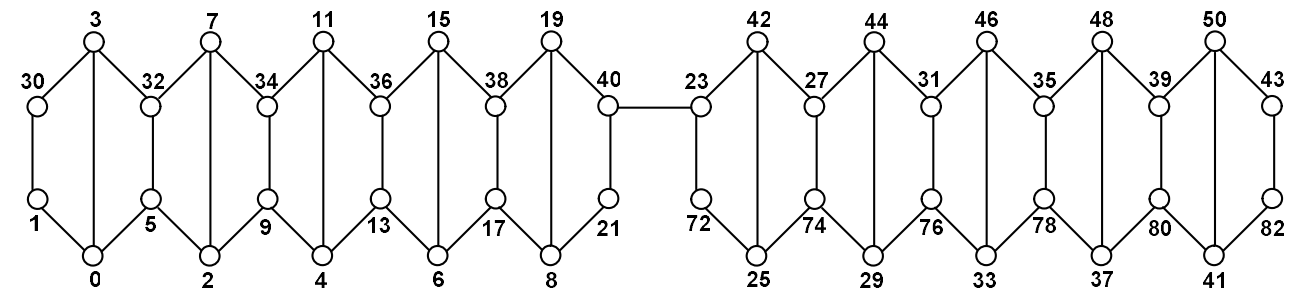

Figure 5. Odd harmonious labeling on a graph $\circledast\left(D Q(5), L_{2}, D Q(5)\right)$

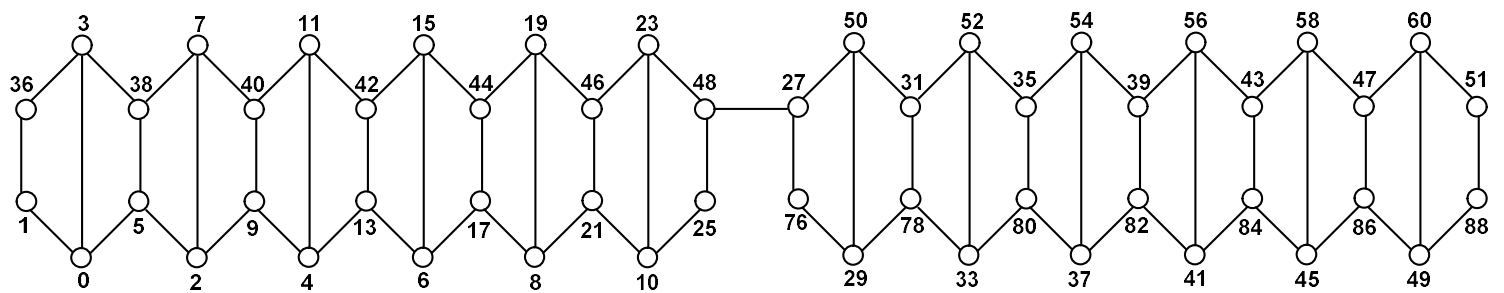

Figure 6. Odd harmonious labeling on a graph $\circledast\left(D Q(6), L_{2}, D Q(6)\right)$

When comparing the results of this study with previous relevant research, similarities and differences are obtained. The similarity lies in the results of this study, which have been proven that graphs $\circledast D Q(n)$ and graphs $\circledast$ $\left(D Q(n), L_{2}, D Q(n)\right)$ is part of the odd harmonious family of graphs, the proof of which can be seen in Theorem 1 and Theorem 2. While the difference lies in different research objects. The graph class observed is a new graph class resulting from the development of edge amalgamation operations from the double quadrilteral graph $D Q$, can be seen in Definitions 1 and Definition 2.

\section{CONCLUSIONS AND SUGGESTIONS}

Based on the results and discussion, it can be concluded that graph $\circledast D Q(n)$ that is, the graph obtained from the results of $n$ double quadrilateral $D Q$ with edge amalgamation operations is an odd harmonious graph. The other side is graph 
Desimal, 3 (1), 2020 - 71

Fery Firmansah, Tasari

$\circledast\left(D Q(n), L_{2}, D Q(n)\right)$ that is, the graph obtained by connecting between two graphs $\circledast D Q(n)$ with line graphs $L_{2}$ also an odd harmonious graph.

Furthermore, this research can be developed by finding the odd harmonious labeling construction of graphs $\circledast$ $\left(D Q(n), L_{2}, D Q(n), \ldots, L_{2}, D Q(n)\right)$ that is, the graph obtained by connecting between $m$ graph $\circledast D Q(n)$ with $m-1$ line graph $L_{2}$.

\section{REFERENCES}

Firmansah, F. (2016). Pelabelan Harmonis Ganjil pada Gabungan Graf Ular dan Graf Ular Berlipat. Konferensi Nasional Penelitian Matematika Dan Pembelajarannya (KNPMP I)an , 809818. Retrieved from https://publikasiilmiah.ums.ac.id/bit stream/handle/11617/7026/88_4_ Makalah Rev Fery Firmansah.pdf? sequence $=1$ \&isAllow ed=y

Firmansah, F. (2017). The Odd Harmonious Labeling on Variation of the Double Quadrilateral Windmill Graphs. Jurnal Ilmu Dasar, 18(2), 109. https://doi.org/10.19184/jid.v18i2. 5648

Firmansah, F., \& Syaifuddin, M. W. (2018). Pelabelan Harmonis Ganjil pada Amalgamasi Graf Kincir Angin Double Quadrilateral. Seminar Nasional Pendidikan Matematika Ahmad Dahlan, 6. Retrieved from http://seminar.uad.ac.id/index.php/ sendikmad/article/view/402

Firmansah, F., \& Wahid Syaifuddin, M. (2018). Pelabelan Harmonis Ganjil pada Amalgamasi Graf Kincir Angin Belanda. Fibonacci Jurnal Matematika Dan Pendidikan Matematika, 4(4), 37-46. https://doi.org/https://doi.org/10.2 4853/fbc.4.1.37-46

Firmansah, F., \& Yuwono, M. R. (2017a). Odd Harmonious Labeling on Pleated of the Dutch Windmill Graphs. Cauchy Jurnal Matematika Murni Dan Aplikasi, 4(4), 161-166. https://doi.org/10.18860/ca.v4i4.40 43

Firmansah, F., \& Yuwono, M. R. (2017b). Pelabelan Harmonis Ganjil pada Kelas Graf Baru Hasil Operasi Cartesian Product. Jurnal Matematika Mantik, 3(2), 87-95. https://doi.org/10.15642/mantik.20 17.3.2.87-95

Gallian, J. A. (2019). A Dynamic Survey of Graph Labeling. The Electronic Journal of Combinatorics, 18.

Jeyanthi, P., Philo, S., \& Siddiqui, M. K. (2019). Odd harmonious labeling of super subdivision graphs. Proyecciones, 38(1), 1-11. https://doi.org/10.4067/S071609172019000100001

Jeyanthi, P., Philo, S., \& Youssef, M. Z. (2019). Odd harmonious labeling of grid graphs. Proyecciones, 38(3), 412416.

https://doi.org/10.22199/issn.0717 -6279-2019-03-0027

Liang, Z.-H., \& Bai, Z.-L. (2009). On the odd harmonious graphs with applications. Journal of Applied Mathematics and Computing, 29(1-2), 105-116. https://doi.org/10.1007/s12190008-0101-0

Saputri, G. A., Sugeng, K. A., \& Froncek, D. (2013). The odd harmonious labeling of dumbbell and generalized prism graphs. AKCE International Journal of Graphs and Combinatorics, 10(2), 221-228. 
Desimal, 3 (1), 2020 - 72

Fery Firmansah, Tasari 